\title{
Projeto e Anúncio da Geografia Física ${ }^{5}$
}

\author{
[Entwurf und Ankündigung der physischen Geographie - 1757]
}

\author{
Immanuel Kant
}

O gosto racional de nossos tempos esclarecidos parece que se tornou tão universal, que podemos pressupor que serão encontrados apenas poucos aos quais seria indiferente conhecer aquelas curiosidades da natureza, que o globo terrestre compreende em si também em outras regiões [Gegenden], as quais não podem ser vistas sem nenhuma prioridade, pois a admiração crédula, a tutora de alucinações infinitas, abriu caminho ao exame cuidadoso, através do qual somos colocados em condições de retirar conhecimentos seguros partindo de comprovações autênticas, sem corrermos o perigo de nos perder num mundo de fábulas ao invés da obtenção de uma ciência correta das curiosidades da natureza.

A consideração da Terra é nomeadamente tríplice. A consideração matemática vê a Terra como um corpo [Weltkörper] de forma aproximadamente esférica e desprovido de criaturas, cujo tamanho, figura e órbita, que precisam ser pensados nele, leva em consideração. A consideração política ensina sobre os povos, a comunidade que os homens têm uns com os outros através da forma de governo, da ação e dos interesses mútuos, a religião, rituais etc.; a Geografia Física considera apenas o arranjo da natureza [Naturbeschaffenheit] do globo terrestre e o que nele é encontrável: os mares, a terra firme [festes Land], as montanhas, rios, as correntes de ar, os homens, os animais, plantas e minerais. Mas tudo isso, não com aquela integridade e exatidão filosófica nas partes, que é um negócio da Física e da História natural, e sim com o novo desejo racional de um viajante que busca por toda a parte o curioso, o singular e o belo, que compara suas observações totais e que repensa seu plano.

Creio ter observado que os dois primeiros tipos de consideração da Terra encontram diante de si recursos suficientes através dos quais um ávido estudioso está em condições de progredir de um modo tanto confortável como satisfatório; apenas uma visão completa e correta na terceira leva consigo mais empenho e obstáculos. As notícias que se

${ }^{5}$ Um alerta inicial torna-se aqui necessário: em função da multiplicidade de significados de alguns vocábulos essenciais do texto, optou-se, sempre que o significado parecia dúbio, por manter o vocábulo em alemão ao lado da melhor solução encontrada, para que a tradução não tirasse do leitor as possibilidades de interpretação que o texto proporciona. 
prestam aqui estão dispersas em muitas e grandes obras e falta ainda uma obra de referência, por meio da qual essa ciência possa ser feita para o uso acadêmico de modo hábil. Por isso, logo no começo de minhas lições acadêmicas, tomei a decisão de proferir essa ciência em preleções especiais, segundo instrução de um projeto sumário. Eu o realizei em um curso semestral para a satisfação de meus senhores ouvintes. Desde então, ampliei meu plano consideravelmente. Extraí de todas as fontes, busquei em toda provisão e além destes, o que as obras de Varenius, Buffon e Luloff contêm de razões gerais da Geografia Física, passei pelas descrições mais fundamentais de hábeis viajantes de países [Länder] específicos, pela revista de Hamburgo e de Leipzig, pelos artigos da Academia de Ciências de Paris e Estocolmo e outras mais e, de tudo que pertencia a este fim, fiz um sistema. Eu forneço aqui um breve projeto disso. Poder-se-á julgar, sem destruir o nome de um sábio, se é permitido ser um ignorante nestas coisas.

\section{Breve Esboço da Geografia Física}

\section{Preparação}

A Terra será considerada brevemente segundo sua figura, tamanho, movimento e a órbita, que por isso precisam ser pensados nela, mesmo sem se aceitar aquela prolixidade que pertence à Geografia matemática. Tudo isso será mostrado no globo e, ao mesmo tempo, de modo resumido, a divisão em mares, terra firma [festes Land] e ilhas, a proporção de seu tamanho, o clima, os conceitos de longitude, de latitude, de duração do dia e das estações do ano.

\section{Tratado}

\section{Parte Geral da Geografia Física}

\section{Primeiro Capítulo}

\section{Sobre o Mar}

Sua divisão em oceano, mares mediterrânicos e lagos. Dos arquipélagos. Dos golfos, estreitos, portos, ancoradouros. Do solo do mar e sua característica. Da profundidade do mesmo em diferentes mares, comparados uns com os outros. Da sonda e do sino mergulhador ${ }^{6}$. Métodos

${ }^{6} \mathrm{O}$ sino mergulhador, em alemão "Taucherglocke", era o instrumento utilizado na época de Kant para a realização de trabalhos debaixo d'água. [N.T.] 
de trazer coisas submersas à tona. Da pressão da água do mar. Da sua salinidade. Diferentes opiniões sobre a causa da mesma. Preparação do sal do mar. Métodos de tornar doce a água do lago. Da transparência, brilho e cor da mesma e das causas de sua diferenciação. Da frieza e calor da mesma em diferentes profundidades. Se o oceano está na mesma altura em todas as suas partes. Por que o mar não fica mais cheio em função dos rios. Se mares e lagos possuem relações subterrâneas. Movimento do mar através das tempestades. Quanto o mesmo se estende em profundidade. Os mares e lagos que são mais agitados. Das marés. Leis e causas das mesmas. Exceção dessas leis. Movimento geral do mar. Como este é determinado diferentemente pelos litorais e rochedos. Das correntes marítimas. Dos redemoinhos do mar. Causas dos mesmos. Do percurso da água nos estreitos. Do mar glacial. Área glacial navegável. Madeira flutuante nórdica ${ }^{7}$. Algumas outras curiosidades. Dos penhascos e bancos de areia. Dos lagos continentais e pântanos. Lagos curiosos como o de Zirknitz $^{8}$ e outros.

\section{Segundo Capítulo}

\section{História da Terra Firme e das Ilhas}

Das terras que são inteiramente ou em parte desconhecidas. As montanhas, serras, a terra firme e as ilhas, consideradas em um conceito sistemático. Dos morros, penínsulas, istmos. Altitude comparada das montanhas mais conhecidas sobre toda a circunferência terrestre. Várias observações em seus picos em diferentes partes do mundo. Das geleiras ou mares glaciais suíços. Métodos de medir sua altitude. Das grutas naturais e artificiais e abismos. Da estrutura do solo9 . Dos estratos de sua matéria, ordenamento e posição. Dos filões de minério. Do calor, frio e do ar em diferentes profundidades. História dos terremotos e montanhas vulcânicas em todo globo terrestre. Consideração das ilhas, tanto daquelas que certamente enquanto tais são reconhecidas, quanto daquelas em que isso é duvidoso.

${ }^{7}$ Fenômeno natural que consiste na acumulação de madeira em um determinado lugar e cujas causas são determinadas pelas correntes de ar, ventos, marés etc. Certamente Kant conhecia também a mitologia nórdica, segundo a qual os dois primeiros seres humanos tiveram origem a partir de duas peças de madeira flutuante. [N.T.]

${ }^{8}$ Em seu primeiro trabalho "Pensamentos acerca da avaliação verdadeira das forças vivas" (Gendanken von der wahren Schätzung der lebendigen Kräfte - 1746), Kant já havia citado esse "curioso lago" na Eslovênia. [N.T.]

9 O vocábulo alemão "Erdklumpel" significa mais precisamente um "pedaço" ou "amostra" de solo. [N.T.] 


\section{Terceiro Capitulo}

\section{História das Fontes e Poços}

Diferentes hipóteses sobre sua origem. Observações a partir das quais a mesma pode ser diferenciada. Fontes que fluem periodicamente. Fontes petrificadas, minerais, quentes e extremamente frias. Da água de cimento $^{10}$. Poços inflamáveis. Do petróleo e nafta. Da transformação, surgimento e desaparecimento das fontes. Do fosso dos poços.

\section{Quarto Capitulo}

\section{História dos Rios e Córregos}

Origem dos rios. Comparação dos mais curiosos na Terra do ponto de vista da posição do seu percurso, de sua velocidade, da quantidade de água; da sua direção, do tamanho de seu talude, enchente, inundação, diques e molhes, dos canais mais conhecidos. Das quedas d'água. Dos rios que se esgotam na terra [Land]. Destes que se ocultam sob a Terra e reaparecem novamente. Dos rios que conduzem grãos de ouro. Métodos de extraí-lo. Dos diferentes pesos da água dos rios.

\section{Quinto Capitulo}

\section{História das Correntes de Ar}

Espessura da atmosfera. As três regiões [Regionen] da mesma. Comparação das propriedades do ar em diferentes regiões [Gegenden] do mundo, do ponto de vista do peso, aridez, umidade, salubridade. Consideração de sua propriedade em grandes altitudes e profundezas. Efeito do ar na luz das estrelas em diferentes áreas [Ländern].

\section{História dos Ventos}

As mais distintas e menores causas dos mesmos. Sua divisão segundo as regiões [Weltgegenden $]^{11}$. Ventos de diferentes propriedades de aridez, umidade, calor, frieza e salubridade. Do vento de passagem, suas leis gerais e especiais, segundo característica das zonas [Erdstriche]. Das monções. Dos ventos irregulares marítimos e terrestres. Dos que predominam o maior tempo em uma região. Da velocidade do vento. Das

${ }^{10}$ Água de cimento (Zementwasser) é conhecida nos dias de hoje como "solução de sulfato de cobre".[N.T.]

${ }^{11}$ Weltgengenden, sinônimo de Himmelsgegenden, pode significar tanto regiões como direções. [N.T.] 
calmarias, das tempestades, furacões, tufões, das trombas d'água e chuvas torrenciais, segundo as regiões do mundo nas quais elas predominam consideradas suas leis e causas. Os ventos em diferentes elevações da Terra comparados uns com os outros. Breve consideração de algumas características especiais do ar.

\section{Sexto Capitulo}

\section{Da Conexão do Tempo com a Zona [Erdstriche] ou com as Estações do Ano em Diferentes Áreas [verschiedenen Ländern]}

Em que consiste o inverno em zonas [Zone] quentes. Por que o inverno ou o verão não acontece ao mesmo tempo e do mesmo modo em todas as zonas da Terra [Erdstrichen] que de algum modo têm o mesmo clima. Onde as zonas quentes são habitáveis. Enumeração das áreas [Länder] que estão sob uma região [Himmelsstriche] ${ }^{12}$, e mesmo do ponto de vista do calor e frieza no oceano do sul, e causas dos mesmos. Das regiões [Gegenden] de maior calor e frio no solo da Terra, os graus e efeitos dos mesmos. Das áreas [Länder] nas quais nunca chove e nas quais chove quase constantemente.

\section{Sétimo Capitulo}

\section{História das Grandes Transformações que a Terra Outrora Sofreu}

a) Das transformações que ainda permanecem

Efeito dos rios na transformação da forma da Terra a partir dos exemplos do Nilo, rio Amazonas, Mississipi e outros. Efeitos da chuva e das enxurradas. Se a terra firme [festes Land] sempre abaixa e o mar pouco a pouco é elevado. Da conseqüência dos ventos na transformação da forma terrestre. Da transformação da mesma através dos terremotos. Através do homem. Comprovação através de exemplos. Da transformação contínua da terra firme em mar e do mar em terra firme. Observações desse fato e opiniões sobre as conseqüências do mesmo. Hipótese de Lineu. Se os movimentos da Terra, tanto os diários como os anuais, são submetidos a uma transformação.

b) Os marcos da transformação da Terra nos tempos mais remotos

12 O vocábulo alemão Himmelsstrich, literalmente traduzido como "zona celeste", era utilizado na linguagem científica antiga e significa o que hoje em dia entendemos por "região geográfica". [N.T.] 
Toda terra firme [festes Land] foi outrora o solo do mar. Comprovação a partir das camadas de concha encontradas na Terra e nas altas montanhas, animais marinhos e plantas marinhas petrificados ou moldados em pedra. Comprovação de Buffon a partir da forma das serras. Que a transformação da terra firme em mar e do mar em terra firme é freqüentemente seguida, em longo período, uma pela outra, comprovado a partir desses estratos que contêm resíduos do chão do mar e que alternam com os que abrangem produtos da terra firme. Das florestas subterrâneas. Posição de suas árvores enterradas. As razões do porque, nessas camadas terrestres, pode-se encontrar resíduos da maior parte dos animais e plantas indígenas ${ }^{13}$. Crítica dos assim chamados jogos da natureza. De suas rochas, as quais realmente são partes petrificadas do reino animal.

c) A Teoria da Terra ou razões da história antiga da mesma

Se uma única inundação geral, como a de Noé, poderia produzir todas essas transformações. Consideração geral da forma da terra firme, da direção e da vertente das serras, dos picos de terra e ilhas, em cuja analogia é realizada na causa de sua origem e de suas transformações. Dedução a partir do arranjo das camadas da Terra e do que elas contêm em si. Se o eixo da Terra se modificou outrora. Crítica das hipóteses de Woodward, Burnet, Whiston, Leibniz, Buffon e outros mais. Resultado a partir das críticas comparadas.

\section{Oitavo Capitulo}

\section{Sobre a Navegação}

Dos rombos, da loxodrômia, da rosa dos ventos, do cálculo dos caminhos e correção dos mesmos. Da invenção da longitude e latitude. Exame da razão [Grund]. Outras curiosidades da navegação. Das viagens marítimas mais curiosas dos tempos antigos e recentes. Da suposição de novas terras [Länder] e os esforços para descobri-las.

\section{Da Parte Especial da Geografia Física}

1. O reino animal, no qual o homem será considerado de um modo comparado, segundo a diferença de sua formação natural e cor, em diferentes regiões [Gegenden] da Terra; em segundo lugar, detêm-se nos animais mais curiosos, tanto os da terra [Land],

\footnotetext{
${ }^{13}$ Kant usa aqui o adjetivo "indianisch-", cujo significado contemporâneo remete ao povo da Índia, mas que possivelmente em sua época era utilizado para qualificar os povos nativos das Américas. [N.T.]
} 
como os do ar, como também os da água; serão considerados os anfíbios e insetos mais curiosos, segundo a história de sua natureza.

2. O reino vegetal, do qual todas aquelas plantas da Terra que chamam atenção, principalmente por sua raridade ou por sua utilidade especial, serão explicadas.

3. O reino mineral, cujas curiosidades mais agradáveis e na maioria das vezes influentes no uso ou prazer humanos serão perpassadas de um modo histórico e filosófico.

$\mathrm{Eu}$ o apresento, em primeiro lugar, na ordem natural de classes e perpasso, por último, no ensino geográfico de todas as áreas [Länder] da Terra, para expor as inclinações dos homens, as quais provêm das regiões [Himmelsstriche] onde vivem, a multiplicidade de seus preconceitos e modos de pensamento, até o ponto em que isso tudo possa servir para tornar o homem mais próximo consigo mesmo, um breve conceito de suas artes, ação e ciência, uma narrativa dos acima já explicados produtos da terra [Land] nos lugares [Orten] a que pertencem, a qualidade do ar etc., em uma palavra, tudo o que se refere à consideração física da Terra.

Tudo será reunido em redações sumariamente escritas, as quais devem servir à fácil repetição dessa ciência que, aliás, mantém suficientemente a atenção por meio de sua compreensibilidade.

A ciência da qual o presente esboço apresenta um projeto será ministrada nesse semestre de verão. Explicarei em aulas especiais também a ciência da natureza [Naturwissenschaft] segundo o método do manual do Senhor Dr. Eberhard. A Lógica será exposta segundo a breve introdução de Meier e a Metafísica segundo a instrução de Baumeister. Empreguei esta mudança no semestre passado, a pedido de alguns dos senhores, com o certamente fundamental, porém, difícil Baumgarten, para vossa satisfação. Ter-se-á, contudo, a liberdade de escolha de qual dos dois esperar-se-á maiores vantagens. Na Matemática, as antigas aulas serão prosseguidas e novas serão iniciadas. Meus esforços serão suficientemente propícios, se eles puderem adquirir a aprovação daqueles que compõem certamente não a maior, mas a mais valiosa parte, a saber, dos racionais. 


\title{
Anexo de uma Breve Consideração
}

\author{
Sobre a Questão:

\begin{abstract}
Se os ventos do oeste em nossa região são úmidos porque passam sobre um grande mar
\end{abstract}

Se quisermos ver a causa das características da natureza que dependem da região [Himmelsgegend] ${ }^{14} \mathrm{e}$ do arranjo das zonas da Terra [Beschaffenheit der Erdstriche], haverá frequentemente o perigo de ver desfazer seu sistema através de uma instância não prevista, se não consultarmos antes os fenômenos e observações comparados a outras áreas [Länder]. Todos nós nos lembramos do tempo úmido que nos chega com o vento do oeste devido à posição de nosso país [Land], a oeste do qual se encontra um grande mar. Isolada, essa explicação aparentemente tão simples, tão natural, tornar-se-á muito duvidosa por meio da comparação com o tempo de outros países [Länder], se não inteiramente refutada. Musschenbroeck, que é senão de certo modo da mesma opinião, fica, contudo, um pouco incerto quanto a isso, quando ele considera que o vento do norte é um vento seco nos Países-Baixos, se ele próprio passa sobre o grande mar alemão e mesmo sobre o oceano nórdico. Ele atribui a sua aridez ao frio do mesmo. Somente se no verão o sol aquecer suficientemente esse oceano, aí então não se realizará esse subterfúgio e o vento lhe permanecerá, não obstante, seco. Contudo, encontramos ainda na Geografia Física razões mais fortes contra a opinião comum.

Em todo o Oceano Índico, partindo dos arquipélagos das Filipinas até o Mar Arábico, predominam, ao longo do ano, dois ventos sazonais: o vento nordeste de outubro a maio e o vento sudoeste de maio a outubro. O primeiro leva consigo um ar limpo e o último é a causa dos meses de chuva nessas áreas [Länder], embora tanto um quanto o outro passe sobre o mar. Nas ilhas das Filipinas, em Mindanao e nas demais, isso fica ainda mais visível. A monção do leste vem sobre o mar calmo quase sem limite e consegue, por conseguinte, tornar o tempo limpo. Ao contrário, o vento sazonal do oeste, que passa sobre regiões salpicadas de ilhas e montanhas, leva consigo o período de chuva. Kolbe alega que no cabo da Boa Esperança, tanto na região a ele pertencente a oeste quanto a leste, os ventos do leste conseguem tornar o tempo seco, porém, os ventos do oeste trazem a estação chuvosa, embora não possa ser visto o por que o vento do oeste deveria ser simplesmente úmido, já que a leste encontra-se um mar

${ }^{14}$ Ver nota 11. [N.T.] 
do mesmo modo extenso como o do oeste. No golfo do México, no istmo do Panamá, em Cartagena e em outras partes, assim como no Mar Índico, os ventos NE e os ventos WSW revezam ao longo de dois semestres. Os primeiros, os quais denominamos de brisas, são secos e fazem um ar limpo. Os últimos, os quais chamamos de vendavais, são úmidos e com eles vem o período de chuva. Mas então vêm os ventos NE sobre o grande Oceano Atlântico e são, contudo, secos. Todavia, os ventos WSW (oestesudoeste) não podem provir de nenhuma grande zona do mar calmo, porque, num afastamento mediano da terra firme, ventos do leste permanentes dominam esse lago. Na viagem que a embarcação manilhense promove de Acapulco a Manilha e aí, para usufruir do vento do leste, não se distancia tanto do Equador, ela encontra quase constantemente o tempo limpo. Apenas na viagem de Manilha a Acapulco, já que conduz a uma certa altitude sobre a circulação de vento do norte, ela dirige para a América com ajuda do próprio vento do oeste predominante, e é tão certo que encontre chuvas freqüentes, que nem se abastece de água nessa longa viagem, e todos estariam perdidos, se elas deixassem de vir. Agora, digame: se afirmarmos a opinião comum de uma causa compreensível do por que o vento do leste, que passa no mar calmo e certamente na região mais quente, teria que ser apenas seco, então por que o vento do oeste, que sopra sobre o mesmo Oceano, teria que ser úmido e chuvoso.

Parece-me que isso é mais que suficiente para ao menos duvidar do pensamento de que aqui os ventos do oeste captam sua umidade do mar situado a oeste. Contudo, parece que os ventos do oeste são, em todas as regiões [Gegenden] da Terra, uma causa do tempo úmido, ainda que eu mesmo não esteja de acordo, que o arranjo das regiões [Beschaffenheit der Gegenden] sobre as quais eles passam, possa às vezes reduzir essa propriedade, assim como acontece na parte sul da Pérsia, onde os ventos sudoeste que chegam sobre as regiões [Gegenden] aquecidas da Arábia, levam consigo ar seco e quente. O rigor do espaço me impede de esclarecer as causas dessa propriedade dos ventos do oeste. Já que passam no sentido contrário do percurso geral e natural do ar de leste a oeste - fato que será explicado no quarto capítulo da Geografia Física, e de algum modo por causa disso, não deveriam os mesmos reunir e aumentar os vapores, para que o ar de cada período fosse preenchido? No mínimo, se se vê o ar como um meio de solução [mestruum] à umidade na Terra, assim, não será suficiente aceitá-lo preenchido por ela até a saturação, se se quiser explicar, por que ele a deixa precipitar, isto é, porque chove, mas sim precisa-se apontar uma causa que a faça precipitar, ou seja, que o ar necessita deixá-la dirigir-se aos seus entre-espaços [Zwischenräumen], para que os vapores possam se unir e precipitar. 


\title{
Notícia do Sr. Prof. Immanuel Kant sobre a Organização de suas Preleções no Semestre de Inverno de 1765-1766 ${ }^{15}$
}

\author{
[M. Immanuel Kants Nachricht von der Einrichtung \\ seiner Vorlesungen in dem Winterhalbenjahre von 1765-1766]
}

Immanuel Kant

Todo ensino da juventude envolve em si a dificuldade de que somos forçados a nos antecipar aos anos com o discernimento e, sem esperar pela maturidade do entendimento, devemos transmitir tais conhecimentos que, segundo a ordem natural, poderiam ser compreendidos apenas por uma razão exercitada e experimentada. Disso originam-se os eternos preconceitos das escolas, que são mais tenazes e muitas das vezes mais desenxabidos que os comuns, bem como a tagarelice precoce dos jovens pensadores, mais cega do que qualquer outra arrogância e mais insanável do que a ignorância. Contudo, esta dificuldade não pode ser inteiramente evitada, pois, no período de uma constituição civil tão enfeitada, os discernimentos mais sutis pertencem aos meios de avançar e tornam-se necessidades [Bedürfnisse] que, por sua natureza, deveriam realmente ser colocadas entre os adornos da vida e como que entre as belezas supérfluas dela. No entanto, é possível, também neste ponto, tornar o ensino público mais cômodo segundo a natureza, senão harmonizando-o inteiramente com esta. Pois visto que o progresso natural do conhecimento humano é tal que, primeiramente, o entendimento se forma, na medida em que chega pela experiência [Erfahrung] a juízos intuitivos [anschauenden Urteilen] e, por meio destes, a conceitos [Begriffen], conceitos estes que, em seguida, são colocados pela razão [Vernunft] em relação com as razões [Gründen] e conseqüências deles, para serem finalmente discernidos [erkannt] por meio da ciência num todo bem ordenado, assim o ensino terá que tomar também

${ }^{15}$ A tradução do presente texto foi cotejada com e deve muito à realizada pelo Prof. Dr. Guido de Almeida, do Departamento de Filosofia da UFRJ - contida sob a forma de anexo em sua tradução das preleções de Lógica de Kant (KANT, Immanuel. Lógica. 3.ed. Trad. Guido Antônio de Almeida. Rio de Janeiro: BTU, 2003.) - cuja permissão para a reprodução nos fora gentilmente concedida, mas infelizmente impossibilitada pela Editora por questões burocráticas. O texto original encontra-se em: KANT, Immanuel. M. Immanuel Kants Nachricht von der Einrichtung seiner Vorlesungen in dem Winterhalbenjahre von 1765-1766. In.: KANT, Immanuel. Kants gesammelte Schriften. Berlin: Preussischen und Deutschen Akademie der Wissenschaft, 1902, vol. II, p. 303313. 
o mesmo caminho. De um professor espera-se, portanto, que ele forme em seu ouvinte, primeiro, o homem [Mann] sensato, depois o racional e, por fim, o douto. Tal procedimento tem a vantagem de que o aprendiz, mesmo que jamais tenha alcançado o último grau, como geralmente acontece, tenha ganhado com o ensino e se tornado mais exercitado e mais inteligente, senão perante a escola, certamente perante a vida.

Se se inverte esse método, o aluno abocanha um tipo de razão [Vernunft] antes mesmo que o entendimento [Verstand] nele seja formado, tornando-se portador de uma ciência de empréstimo, que nele estará como que apenas colada e não desenvolvida, de modo que suas aptidões mentais permanecerão tão inférteis como dantes, tendo se tornado, porém, com o delírio da sabedoria [Weisheit], muito mais corrompidas. Esta é a causa pela qual se encontra, não raro, pessoas doutas (na realidade instruídas) que demonstram pouco entendimento, bem como o porquê as Academias põem no mundo mais cabeças desenxabidas do que qualquer outra instituição da coisa pública.

A regra do comportamento é, portanto, a seguinte: antes de qualquer coisa, amadurecer o entendimento [Verstand] e acelerar seu crescimento, exercitando-o nos juízos da experiência [Erfahrungsurteilen] e despertando a atenção para aquilo que as sensações comparadas [verglichene Empfindungen] de seus sentidos [Sinne] possam lhe ensinar. Partindo destes juízos [Urteilen] ou conceitos [Begriffen], ele não deve empreender nenhum vôo em direção a outros mais elevados e mais distantes, mas deve chegar até aí para a calçada natural e transitável dos conceitos inferiores [niedrigern Begriffe] que aos poucos o levem mais longe; tudo, porém, em conformidade com aquela faculdade do entendimento [Verstandesfähigkeit] que o exercício precedente houver necessariamente produzido nele e não em conformidade com aquela que o professor percebe, ou crê perceber, em si mesmo e que ele erroneamente também pressupõe em seu ouvinte. Em suma, ele não deve ensinar pensamentos, mas a pensar; não se deve carregá-lo, mas guiá-lo, se se quiser que ele seja apto no futuro a caminhar por si próprio.

A própria natureza da Filosofia [Weltweisheit] exige semelhante didática. Porém, visto que esta é propriamente uma ocupação para a idade adulta apenas, não é de admirar que surjam dificuldades quando se quiser acomodá-la à aptidão menos exercitada da juventude. $\mathrm{O}$ adolescente que acabou sua formação escolar estava acostumado a aprender. Ele pensa que, de agora em diante, vai aprender Filosofia [Philosophie], o que, porém, é impossível, pois ele deve agora aprender a filosofar. Gostaria de me explicar com mais clareza. Todas as ciências que a gente pode no entendimento [Verstand] próprio aprender, podem se reduzir a dois 
gêneros: o histórico e o matemático. Entre as primeiras encontram-se, além da própria História [Geschichte], a Descrição da Natureza [Naturbeschreibung], a Filologia, o Direito Positivo etc., etc... Ora, visto que em tudo o que é histórico, é experiência própria ou testemunho alheio, ao passo que em tudo o que é matemático, a evidência dos conceitos e a infalibilidade da demonstração constituem algo que está de fato dado e de que, por conseguinte, estamos aprovisionados e que é preciso apenas apanhar, nos dois casos é possível aprender, isto é, imprimir na memória [Gedächtnis] ou no entendimento [Verstand], aquilo que pode ser posto diante de nós como uma disciplina pronta e acabada. Portanto, para aprender também Filosofia [Philosophie], seria preciso que realmente já houvesse uma. Teria que ser possível exibir um livro e poder dizer: observai, eis aqui sabedoria [Weisheit] e discernimento fidedigno; procurai entendê-lo e assimilá-lo, sobre isso edificai no futuro, sereis então filósofos; até que me mostrem tal livro da Filosofia [Weltweisheit], ao qual eu possa recorrer como, por exemplo, ao Políbio, para elucidar um fato histórico, ou ao Euclides, para explicar uma proposição da Matemática [Größenlehre], seja-me permitido dizer que é um abuso da confiança da coisa pública, quando - ao invés de ampliar a capacidade intelectual dos jovens que nos foram confiados e de formá-los para um discernimento próprio mais amadurecido no futuro - os enganamos com uma Filosofia [Weltweisheit] pretensamente já pronta, que teria sido excogitada por outros em seu benefício, donde resulta um simulacro de ciência que só é válido como moeda autêntica em certo lugar [Orte] e entre certas pessoas, mas que é desacreditada em qualquer outra parte. O método peculiar de ensino na Filosofia [Weltweisheit] é zetético como lhes chamavam os

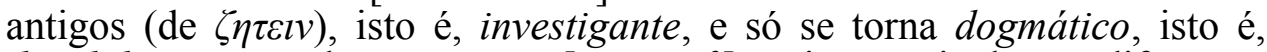
decidido no caso de uma razão [Vernunft] mais exercitada em diferentes questões. Também o autor filosófico em que nos baseamos no ensino deve ser considerado, não como o modelo do juízo, mas apenas como o ensejo de julgarmos nós próprios sobre ele e até mesmo contra ele; e o método de refletir e concluir por conta própria é aquilo cujo domínio o aprendiz a rigor busca, o qual também é o único que lhe pode ser útil, e do qual os discernimentos decisivos que por ventura se tenham obtido ao mesmo tempo têm que ser considerados como conseqüências contingentes dele, conseqüências estas para cuja plena abundância ele só tem de plantar em si mesmo a raiz fecunda.

Se a isso compararmos o procedimento comum tão diverso dele, poderemos compreender várias outras coisas que de outro modo parecem estranhas aos nossos olhos. Como, por exemplo, por que não há nenhuma espécie de sapiência do ofício onde tantos mestres são encontrados como na Filosofia [Philosophie], e, ao passo que muitos dos que aprenderam 
História [Geschichte], Direito, Matemática [Mathematik] etc., se conformam com o fato de apesar disso ainda não terem aprendido o bastante para ensiná-las, por que, por outro lado, raramente se encontra alguém que não se imagine com toda seriedade capaz, além de sua ocupação restante, de ensinar Lógica, Moral e coisas semelhantes, caso quisesse se meter em tais miudezas. A causa é que, naquelas ciências, há um padrão comum, nesta, porém, cada um tem o seu. Do mesmo modo ver-se-á claramente que é muito pouco natural que a Filosofia [Philosophie] seja um ganha-pão, na medida em que repugna ao seu caráter essencial acomodar-se à ilusão da demanda e à lei da moda, e que só a necessidade [Notdurft], cuja força [Gewalt] ainda se faz sentir sobre a Filosofia [Philosophie], pode forçá-la a amoldar-se à forma do aplauso comum.

Aquelas ciências, as quais tenciono apresentar e tratar completamente no semestre que ora se inicia, em lições privadas, são as seguintes:

1. Metafísica. Procurei mostrar num texto breve e apressadamente redigido*, que esta ciência, a despeito dos grandes esforços dos sábios em prol dela, ainda é tão imperfeita e insegura, porque o procedimento peculiar da mesma tem sido ignorado, na medida em que este não é sintético, como o da Matemática [Mathematik], mas analítico. De acordo com este, o simples e o mais geral na Matemática [Größenlehre] também é o mais fácil; na ciência principal [Hauptwissenschaft], porém, o mais difícil; naquela, ele deve por sua natureza vir primeiro, nesta por último. Naquela, começa-se a doutrina pelas definições, nesta é com elas que se termina, e do mesmo modo em vários outros pontos. Há muito, venho trabalhando com base nesse projeto e, na medida em que a cada passo por essa via vou descobrindo as fontes dos erros e a norma do juízo pela qual eles podem ser evitados - se jamais for possível evitá-los - espero poder em breve expor completamente aquilo que pode me servir para a fundamentação da minha apresentação na mencionada ciência. Até lá, porém, posso muito bem, graças a uma pequena inflexão do rumo, encaminhar no mesmo sentido o autor, A.G. Baumgarten, cujo compêndio escolhi por causa, sobretudo, da sua riqueza e da precisão de sua didática. Assim, depois de uma breve introdução, começo com a Psicologia empirica [empirischen Psyschologie], a qual é a rigor a ciência metafísica empírica do homem; pois, no que concerne à expressão da alma [Seele], neste capítulo ainda não é lícito afirmar que ele tenha uma. $\mathrm{O}$ segundo

\footnotetext{
16* O segundo dos tratados da Real Academia de Ciências em Berlim editou por ocasião do prêmio para o ano de 1763 .
} 
capítulo, que deve tratar em geral da Natureza corpórea [körperlichen Natur], tomo-o de empréstimo às principais partes da Cosmologia, onde se trata da matéria, e que também completarei por alguns acréscimos escritos. Ora, visto que na primeira ciência (à qual também se acrescenta, por causa da analogia, a Zoologia empírica, isto é, a consideração dos animais) se examinou toda a vida que cai sob os nossos sentidos, na segunda, porém, tudo o que é inanimado em geral, e visto que todas as coisas do mundo podem ser reduzidas a essas duas classes, passo em seguida para a Ontologia, a saber, para a ciência das propriedades mais gerais de todas as coisas, cuja conclusão contém a distinção entre os seres espirituais e materiais, bem como a conexão ou a separação dos dois e, portanto, a Psicologia racional [vernünftige Psyschologie]. Aqui, de agora em diante, tenho a grande vantagem de não apenas introduzir na mais difícil dentre todas as investigações filosóficas um ouvinte já exercitado, mas também, ao examinar em cada consideração o abstrato contido naquele Concreto que as disciplinas precedentes fornecem, a vantagem de colocar tudo que na maior clareza, sem me antecipar a mim mesmo, isto é, sem ter o direito de recorrer para a explicação a algo que só futuramente vai ocorrer, o que é o erro comum e inevitável da apresentação sintética. Por fim, vem a consideração da causa de todas as coisas, isto é, a ciência de Deus e do mundo. Não posso deixar de mencionar uma vantagem que se baseia apenas, é verdade, em causas fortuitas, mas que nem por isso deve ser pouco estimada e que penso extrair desse método. Todos sabem com que entusiasmo o início das aulas é feito pela juventude alegre e inconstante e como em seguida as salas de aulas vão aos poucos ficando mais espaçosas. Se eu suponho agora que aquilo que não deve acontecer voltará sempre, no entanto, a acontecer no futuro a despeito de toda lembrança, então a mencionada didática há de conservar uma utilidade peculiar a ela. Pois o ouvinte, cujo entusiasmo já houvesse evaporado lá pelo final da Psicologia empírica (o que, porém, dificilmente se há de presumir no caso dessa maneira de proceder) teria não obstante ouvido alguma coisa que seria compreensível por sua facilidade, aprazível pelo interesse que desperta e útil pelos casos freqüentes de aplicação na vida; ao passo que, a Ontologia, uma ciência difícil de se entender, o tivesse desanimado de continuar, o que ele houvesse compreendido não lhe poderia ser muito útil para nada mais.

2. Lógica. Desta ciência há a rigor dois gêneros. A do primeiro é uma crítica e norma do bom-senso [gefunden Verstand], na medida em que este confina por um lado com os conceitos grosseiros e com a ignorância, mas por outro lado com a ciência e a erudição. A Lógica dessa espécie é aquilo que se deve colocar no início do ensino acadêmico de toda Filosofia [Philosophie], como que a quarentena (se posso me exprimir assim), que 
deve cumprir o aprendiz que queira passar da terra [Lande] do preconceito e do erro para o domínio da razão esclarecida e das ciências. O segundo gênero de Lógica é a crítica e a norma da própria sapiência e jamais pode ser tratada de outra maneira, senão após as ciências cujo Organon ela deve ser, para que se torne mais regular o procedimento de que se utilizou na prática e para que se discirna a natureza da disciplina juntamente com os meios de seu aperfeiçoamento. Assim, acrescento ao final da Metafísica uma consideração sobre o método peculiar da mesma, enquanto Organon dessa ciência, o qual, se colocado no começo desta, não estaria em seu lugar [Stelle] correto, na medida em que é impossível tornar claras as regras se não dispomos de exemplos com os quais se possa mostrá-los in concreto. Claro que o professor deve de antemão ter em mente o Organon, antes de expor a ciência, para que ele próprio se oriente, mas ao ouvinte ele jamais deve apresentá-lo a não ser por último. A crítica e a norma da Filosofia inteira [gesammten Weltweisheit] enquanto um todo, essa Lógica completa, só pode encontrar, pois, o seu lugar [Platz] no ensino ao final da Filosofia inteira [gesammten Philosophie], pois só os conhecimentos já adquiridos da mesma e a História [Geschichte] das opiniões humanas tornam possível fazer considerações sobre a origem de seus discernimentos, bem como de seus erros, e traçar o plano exato segundo o qual semelhante edifício da razão [Vernunft] deve ser erigido de maneira duradoura e regular.

Apresentarei a Lógica do primeiro tipo, seguindo, aliás, o manual do senhor professor Meier, pois este não perde de vista os limites dos objetivos pensados e, ao mesmo tempo, enseja a compreensão, ao lado da cultura da razão mais fina e douta, mas também da formação do senso comum, é verdade, porém ativo e bom, aquela para a vida contemplativa, esta para a vida ativa e civil. Ao mesmo tempo, a afinidade muito próxima da matéria dá ensejo, quando da crítica da razão, a lançar uma vista d'olhos à crítica do gosto, isto é, à Estética, as regras de uma servindo para elucidar as regras da outra e o seu contraste sendo um meio de melhor compreender a ambas.

3. Ética. - A Filosofia moral [moralische Weltweisheit] tem esse destino peculiar de assumir, antes mesmo que a Metafísica, a aparência de ciência e um certo ar de trabalho feito a fundo, se bem que nenhuma dessas duas coisas possam ser encontradas nela; a razão disso é que a distinção do bom e do mau nas ações [Handlungen] e o juízo sobre a legitimidade moral podem ser fácil e corretamente discernidos pelo coração humano de uma maneira direta e sem o rodeio das provas, graças àquilo que se chama sentimento [Sentiment]; assim, a questão já tendo sido no mais das vezes decidida antes dos argumentos racionais, o que não acontece na Metafísica, 
não admira que a gente não se mostre particularmente relutante a deixar passar como prestantes razões que só têm uma aparência de solidez. Por isso, nada mais comum do que o título de filósofo moral, e nada mais raro do que merecer semelhante nome.

Por ora, apresentarei a Filosofia prática geral [allgemeine praktische Weltweisheit] e a Doutrina da Virtude [Tugendlehre], ambas segundo Baumgarten. Os ensaios de Shaftesbury, Hutcheson e Hume, que, embora incompletos e falhos, são os que, no entanto, mais longe chegaram na busca dos fundamentos primeiros de toda moralidade, receberão aquela precisão e complementação que lhes faz falta e, considerando sempre de uma maneira histórica e filosófica na Doutrina da Virtude aquilo que acontece, antes de indicar o que deve acontecer, tornarei claro o método segundo o qual é preciso estudar o homem [Mensch]: não somente aquele que foi deformado pela figura mutável que seu estado contingente imprimiu nele e que enquanto tal ficou quase sempre ignorado dos próprios filósofos; mas a natureza do homem [Mensch] que sempre permanece e sua posição peculiar na criação, para que se saiba qual perfeição lhe é adequada no estado da simplicidade rude e qual no estado da simplicidade sábia, e qual ao contrário a norma de seu comportamento quando, abandonando ambos os limites, trata de tocar o grau supremo da excelência física ou moral, porém, desviando-se mais ou menos de ambas. Este método da investigação moral é uma bela descoberta de nossos tempos e, se o consideramos em seu plano completo, permaneceu inteiramente desconhecido aos antigos.

4. Geografia física. - Quando reconheci, bem no começo de meu ensino acadêmico, que uma grande negligência da juventude estudantil consistia, sobretudo, em aprender cedo a arrazoar, sem possuir conhecimentos históricos [historische Erkenntnisse] suficientes que pudessem representar o lugar [Stelle] da experimentalidade [Erfahrenheit], concebi o plano de fazer da História [Historie] do estado atual da Terra, ou da Geografia [Geographie] no sentido mais lato, uma alta-representação [Inbegriff] agradável e fácil daquilo que ela poderia preparar para uma razão prática [praktischen Vernunft] e que pudesse servir para despertar o prazer de ampliar cada vez mais os conhecimentos aí iniciados. Denominei aquela disciplina daquela parte para a qual se voltava meu principal interesse: Geografia física [physische Geographie]. Desde então, ampliei pouco a pouco esse projeto e tenciono agora, concentrando mais aquela parte que se ocupa das especificidades físicas da Terra, ganhar tempo para me estender mais ao discorrer sobre as outras partes da mesma que têm uma utilidade geral ainda maior. Essa disciplina será, pois, uma Geografia fisica, moral e politica [physische, moralische und politische Geographie], 
na qual serão primeiramente indicadas as especificidades da natureza através de seus três reinos, mas escolhendo aquelas entre inúmeras outras que se oferecem principalmente à curiosidade geral graças ao atrativo de sua raridade, ou graças também à influência que tem sobre os Estados [Staaten] por intermédio do comércio e da indústria. Esta parte, que contém ao mesmo tempo a relação natural entre todos os países [Länder] e mares e a base de sua conexão, é o verdadeiro fundamento de toda a História [Geschichte], sem o qual ela pouco se distingue dos contos lendários; a segunda parte considera o homem [Mensch] na Terra inteira segundo a multiplicidade de suas qualidades naturais e a diferença daquilo que nele é moral; uma consideração muito importante e igualmente cheia de atrativos, sem a qual se podem fazer juízos gerais sobre o homem [Mensch] e onde a comparação recíproca e com o estado moral dos tempos mais antigos desdobra ante os nossos olhos um grande mapa da raça humana. Por último, tratar-se-á daquilo que pode ser considerado como uma conseqüência a partir da interação de ambas as forças anteriormente mencionadas, a saber, a situação dos Estados [Staaten] e povos [Völkerschaften] sobre a Terra, não tanto na medida em que depende das causas contingentes do empreendimento e do destino de homens particulares [einzelner Menschen], como, por exemplo, a sucessão dos governos, as conquistas ou intrigas políticas, mas em relação com aquilo que é mais constante e contém o fundamento remoto daqueles, a saber, a posição [Lage] de suas terras [Länder], os produtos, costumes, indústria, negócios e população. Até mesmo o rejuvenescimento, se assim posso dizer, de uma ciência de tão amplas perspectivas segundo uma escala pequena tem a sua grande utilidade, na medida em que só por meio disso se alcança unidade do conhecimento, sem a qual todo saber não passa de uma obra fragmentária. Não terei o direito, num século sociável como é o atual, de colocar a provisão, que uma grande multiplicidade de conhecimentos agradáveis e instrutivos e de fácil compreensão oferece para a manutenção do convívio social, entre as utilidades que ter em vista não é nenhum desdouro para a ciência? Pelo menos, não pode ser agradável para uma pessoa douta ver-se muitas vezes no embaraço em que se encontrou o orador Isócrates, o qual, ao ser animado numa reunião social a falar alguma coisa, teve que dizer: o que sei não convém, e o que convém não sei.

Esta é a breve indicação das ocupações que consagro no semestre que se inicia à Academia e que só estimei necessária para que se pudesse fazer uma idéia do tipo de ensino no qual tive por bem proceder agora a 
uma modificação. Mihi usus est: Tibi, quod opus est facto, face (Terêncio).*

17* A edição da Academia corrige: Mihi sic est usus: Tibi ut opus facto est, face. ("Para mim assim é que é preciso; quanto a ti, faz como for preciso") [Nota da já mencionada tradução realizada pelo professor Dr. Guido de Almeida] 


\section{Sumário da "Physische Geographie"}

[Physische Geographie, herausgegeben von Friedrich Theodor Rink 1802]

Immanuel Kant

\section{PRIMEIRO VOLUME}

Prefácio do organizador

Introdução

Conceitos matemáticos preliminares

PRIMEIRA PARTE

Primeiro Capítulo: Da água

Segundo Capítulo: Da terra

Terceiro Capítulo: Atmosfera

Quarto Capítulo: História das grandes transformações que a Terra outrora sofreu e ainda sofre

\section{SEGUNDO VOLUME}

SEGUNDA PARTE: Observação especial daquilo que o solo da Terra compreende em si

Primeiro Capítulo: Do Homem

Segundo Capítulo: O reino animal

Primeiro subcapítulo: Aqueles com garras

Segundo subcapitulo: Animais com dedos

Terceiro subcapitulo: Animais com nadadeiras

Quarto subcapitulo: Animais quadrúpedes que põem ovos

Quinto subcapitulo:

1. Animais marinhos

2. Animais com concha

Sexto subcapitulo: Alguns insetos curiosos 
Sétimo subcapitulo: Dos outros animais rastejantes

Oitavo subcapitulo: Dos reinos dos pássaros

Terceiro capítulo: $O$ reino vegetal

Quarto capítulo: O reino mineral

1. Os metais

2. Dos sais

3. Das rochas

4. Dos solos

5. Das petrificações

6. Da origem dos minerais

TERCEIRA PARTE: Consideração sumária das mais distintas curiosidades da natureza de todas as áreas segundo a ordem geográfica
O primeiro continente: Ásia
O segundo continente: África
O terceiro continente: Europa
O quarto continente: America 